\title{
Article
}

\section{The Effect of Solvent on the Liquid - Liquid Extraction of Lanthanides Using DODGAA as an Extractant}

\author{
Kaoru FUJINAGA $^{1 *}$, Yuka KOBAYASHI ${ }^{1}$, Naoto SHIMIZU ${ }^{2}$, Shin-ichi KAWANO ${ }^{3}$, \\ Syunichi OSHIMA ${ }^{1}$, Muneaki SAKAMOTO ${ }^{1}$ and $\mathrm{Yu} \mathrm{KOMATSU}^{4}$ \\ ${ }^{1}$ College of Bioscience and Chemistry, Kanazawa Institute of Technology, \\ 3-1 Yatsukaho, Hakusan, Ishikawa 924-0838, Japan \\ ${ }^{2}$ Agilent Technologies Co. Ltd., 9-1 Takakura-cho, Hachioji, Tokyo 192-8510, Japan \\ ${ }^{3}$ Nomura Micro Science Co. Ltd., 2-9-8 Okada, Atsugi, Kanagawa 243-0021, Japan \\ ${ }^{4}$ Office for Industry-University Collaboration, Kanazawa Institute of Technology, \\ 7-1 Ohgigaoka, Nonoichi, Ishikawa 921-8501, Japan
}

(Manuscript received April 3, 2018; accepted June 25, 2018)

\begin{abstract}
4-Methyl-1,3-dioxolan-2-one and 4-ethyl-1,3-dioxolan-2-one are well-known solvent in the name of propylene carbonate (PC) and butylene carbonate (BC), respectively, and $\mathrm{PC}$ is classified to level 1 in terms of combustibility and health hazard by National Fire -Protection Association. Therefore, PC is less toxic and environment-friendly solvent compared to the usual solvents, such as hexane and toluene. PC and $\mathrm{BC}$ are not only safe but also are having strong polarity, however, their application to solvent extraction of metal chelates as an extraction solvent were not carried out so much. Then, in this study, PC and BC were applied to N,N-dioctyldiglycolamic acid (DODGAA) extraction of lanthanides as the diluent and their extractabilities were compared with that of hexane. Lanthanum and scandium were found to be affected with solvent comparatively strongly to the other lanthanides. It was observed in the slope analysis of in the relationship between $\log D$ vs. pH plots that the some slopes of straight lines in DODGAA-PC and DODGAA-BC system deviated from theoretical value of 3 . The possibilities of the change of metal ion concentration based on the volume change due to the mutual dissolution and the formation of different kind of complex other than $\mathrm{LnR}_{3}$ were considered as the causes for the deviations in a slope analysis and were examined experimentally.
\end{abstract}

Keywords: Propylene carbonate, Butylene carbonate, Solvent extraction of lanthanides, DODGAA

\section{Introduction}

In the liquid-liquid extraction, solvent plays an important role of not only dissolving the extracted species but also modifying the extractability of analyte. 4-Methyl-1,3-dioxolan2-one (propylene carbonate, PC) and 4-ethyl-1,3-dioxolan-2one (butylene carbonate, $\mathrm{BC}$ ) are an advisable solvent which has good characteristics such as high flush point, heavier than water, polar with dielectric constant of 65.1 (for PC). Moreover, $\mathrm{PC}$ and $\mathrm{BC}$ are assigned in level 1 and 0 as for health, respectively, and both are classified in level 1 as for flammability and level 0 as for instability by National Fire Protection Association ${ }^{1)}$. PC is widely used for cosmetics such as nail polish remover and used in industries as a solvent to extract aromatics from naphtha ${ }^{2}$.

Generally, since the extracting solvent affects to extractability in the ion association extraction systems more strongly than that in chelate extraction system, PC was mainly examined in the former systems. For example, B. G. Stephens

\footnotetext{
* Corresponding author

E-mail: fujinaga@neptune.kanazawa-it.ac.jp
} 
et al. has reported the extraction of ferroin complexes using PC as a solvent with different derivatives of 1,10-phenanthroline ${ }^{3-5)}$, and PC was also used for the extracting solvent in the polarographic determination of halo-complex ions of some metals $^{6,7)}$. On the other hand, only few attempts to applying PC to chelate extraction system were reported ${ }^{8,9)}$, and the paper on the solvent extraction of metal ions using $\mathrm{BC}$ could not be found at all by reviewing the literature.

$\mathrm{PC}$ and $\mathrm{BC}$ were applied to N,N-dioctyldiglycolamic acid (DODGAA) extraction of lanthanides as the diluent in this study, because it was studied in detail under the several extraction conditions ${ }^{10-13)}$ and seemed to be a suitable to evaluate the extractability of solvent.

\section{Experimental}

\subsection{Reagents}

DODGAA and BC were purchased from Tokyo Chemical Industry Co., Ltd. and was used without further purification. PC was obtained from Kanto Chemical Co., Inc. and was used as it was. All other reagents were of analytical grade.

\subsection{Extraction procedure}

Organic phases were prepared by dissolving DODGAA in $\mathrm{PC}$ or in $\mathrm{BC}$ or in hexane containing 5 vol.\% 1-octanol as an solubilizing adjuvant. Aqueous phases contained $0.1 \mathrm{mmol}$ $\mathrm{dm}^{-3}$ of metal ions and $0.1 \mathrm{~mol} \mathrm{dm}{ }^{-3} \mathrm{NH}_{4} \mathrm{NO}_{3}$. The $\mathrm{pH}$ values of the aqueous phases were adjusted using $\mathrm{HCl}$ and $\mathrm{NaOH}$. Five milliliters of the aqueous and organic phases were shaken for $60 \mathrm{~min}$ at $100 \mathrm{spm}$ and then the phases were separated by centrifuge for $20 \mathrm{~min}$ at $2000 \mathrm{rpm}$. The metal ions in the organic phase were back-extracted into $3 \mathrm{~mol} \mathrm{dm}^{-3} \mathrm{HCl}$. The concentration of metal ions in the aqueous phase and in $3 \mathrm{~mol}$ $\mathrm{dm}^{-3} \mathrm{HCl}$ was measured by inductively coupled plasma optical emission spectrometer (ICP-OES, Vista-Pro, Varian).

\subsection{Selection of solvent}

\section{Results and Discussion}

Properties of PC and BC were summarized in Table $\mathbf{1}$ as well as those of usual solvents. PC and BC have higher flash point, higher $E_{\mathrm{T}}$ value and higher dielectric constant than other solvents and their density are higher than water. National Fire

Table 1 Properties of solvents ${ }^{14)}$

\begin{tabular}{|c|c|c|c|c|c|c|c|}
\hline & $\begin{array}{l}\text { Propylene } \\
\text { carbonate }^{1)}\end{array}$ & $\begin{array}{l}\text { 1,2-Butylene } \\
\text { carbonate }^{15)}\end{array}$ & Hexane & Toluene & Nitrobenzene & 1-Octanol & Water \\
\hline $\begin{array}{l}\text { Density } \\
\left(\mathrm{g} / \mathrm{cm}^{3}\right)\end{array}$ & $1.19\left(25^{\circ} \mathrm{C}\right)$ & 1.15 & 0.66 & 0.87 & 1.20 & 0.82 & 1.00 \\
\hline Boiling point $\left({ }^{\circ} \mathrm{C}\right)$ & 240 & $75(0.2 \mathrm{kPa})$ & 68 & 110 & 210 & 194 & 100 \\
\hline Melting point $\left({ }^{\circ} \mathrm{C}\right)$ & -55 & - & -95 & -95 & 6 & -16 & 0 \\
\hline Ignition point $\left({ }^{\circ} \mathrm{C}\right)$ & 455 & 421 & 225 & 480 & 480 & 253 & - \\
\hline Flash point $\left({ }^{\circ} \mathrm{C}\right)$ & 116 & 135 & -22 & 5 & 88 & 83 & - \\
\hline $\begin{array}{l}\text { Solubility in water }{ }^{16)} \\
\qquad\left(25^{\circ} \mathrm{C}, \mathrm{g} / \mathrm{L}\right)\end{array}$ & 175 & - & 0.0095 & 0.52 & 1.90 & 6 & - \\
\hline $\begin{array}{l}\text { Solubility of water in } \\
\text { solvent }(\mathrm{mol} / \mathrm{L})^{17)}\end{array}$ & - & - & $2.58 \times 10^{-3}$ & $2.66 \times 10^{-2}$ & - & 2.09 & - \\
\hline $\begin{array}{c}\text { Dipole moment } \\
\left.\text { (Debye, } 20^{\circ} \mathrm{C}\right)\end{array}$ & 5.00 & - & 0.085 & 0.31 & 4.00 & 1.76 & 1.82 \\
\hline $\begin{array}{c}E_{\mathrm{T}} \text { value } \\
(\mathrm{kcal} / \mathrm{mol})\end{array}$ & 46.1 & 45.8 & - & 33.9 & 41.9 & 48.3 & - \\
\hline $\begin{array}{l}\text { Dielectric constant } \\
\qquad\left(20^{\circ} \mathrm{C}\right)\end{array}$ & 65.1 & - & 1.8 & $2.3\left(25^{\circ} \mathrm{C}\right)$ & 34.8 & 10.3 & 80.2 \\
\hline Hazard & Irritative & - & $\begin{array}{c}\text { Flammability } \\
\text { Noxious } \\
\text { Irritative } \\
\text { Staining }\end{array}$ & $\begin{array}{l}\text { Flammability } \\
\text { Noxious }\end{array}$ & $\begin{array}{l}\text { Toxicity } \\
\text { Staining }\end{array}$ & Irritative & - \\
\hline
\end{tabular}




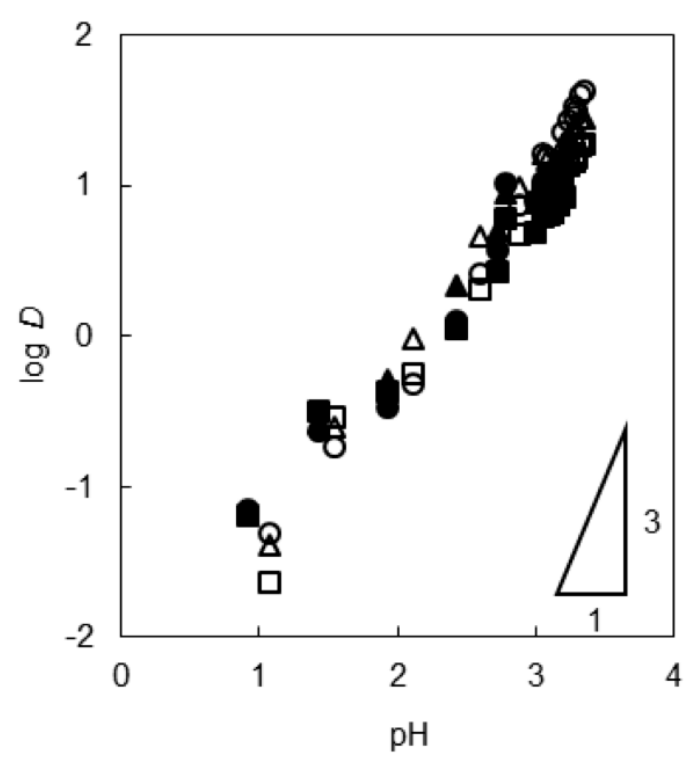

Fig. 1 Effect of shaking time on the extraction of $\mathrm{Y}^{3+}, \mathrm{Eu}^{3+}$ and $\mathrm{Yb}^{3+}$. $\left[\mathrm{Ln}^{3+}\right]=0.1 \mathrm{mmol} \mathrm{dm}{ }^{-3},[\mathrm{HR}]=0.01 \mathrm{~mol} \mathrm{dm}^{-3}$. ๑: Y (24h), $\square$ : Eu (24h), $\triangle$ : Yb (24h), O: Y (1h), $\square:$ Eu (1h), $\triangle: Y b(1 H)$.

Protection Association (NFPA) classifies PC in level 1 for human health and for flammability and in level 0 as for reactivity. PC has been widely used as a solvent for cosmetics like a nail remover and can be considered nontoxic solvent. Although the information of $\mathrm{BC}$ on safety could not be obtained, $\mathrm{BC}$ is considered to be also less toxic compared to the usual solvent judging from the similarity of molecular structure between $\mathrm{PC}$ and $\mathrm{BC}$.

\subsection{Effect of shaking time}

In a preliminary test, it was ascertained that $\mathrm{Y}^{3+}, \mathrm{Eu}^{3+}$ and $\mathrm{Yb}^{3+}$ attained to the equilibrium by shaking for $10 \mathrm{~min}$ in both hexane and PC extraction system, and therefore the shaking time was set to $1 \mathrm{~h}$ in this study. In addition, the effect of shaking time on the extraction of $\mathrm{Ln}^{3+}$ was examined with $\mathrm{BC}$ extraction system and the results were shown in Figs. 1 and 2. As shown in Fig. 1, significant variation in neither slope of the line in $\log D$ vs. $\mathrm{pH}$ nor $\mathrm{pH}_{1 / 2}$ value were observed in the extraction of $\mathrm{Y}^{3+}, \mathrm{Eu}^{3+}$ and $\mathrm{Yb}^{3+}$ by prolonging the shaking time from $1 \mathrm{~h}$ to $24 \mathrm{~h}$. Therefore, it can be said that $\mathrm{Y}^{3+}, \mathrm{Eu}^{3+}$ and $\mathrm{Yb}^{3+}$ quickly attained to the equilibrium in $\mathrm{BC}$ extraction system as well as hexane and PC extraction systems. However, in the case of $\mathrm{Sc}^{3+}$ and $\mathrm{La}^{3+}$, Fig. 2 shows that slope of the line in $\log D$ vs. $\mathrm{pH}$ and $\mathrm{pH}_{1 / 2}$ value were both fairly changed by extending the shaking time. Especially, $\mathrm{pH}_{1 / 2}$ value of $\mathrm{Sc}^{3+}$ shifted from 3.73 to 1.17 , and the slope of line increased from 1.4 to 2.1 with prolonging the shaking time form $1 \mathrm{~h}$ to $24 \mathrm{~h}$, respectively. Based on these results, hereafter, the extractability of $\mathrm{PC}$ and $\mathrm{BC}$ was mainly examined with $\mathrm{Y}^{3+}$, $\mathrm{Eu}^{3+}$ and $\mathrm{Yb}^{3+}$ under the experimental condition of $1 \mathrm{~h}$ shaking.

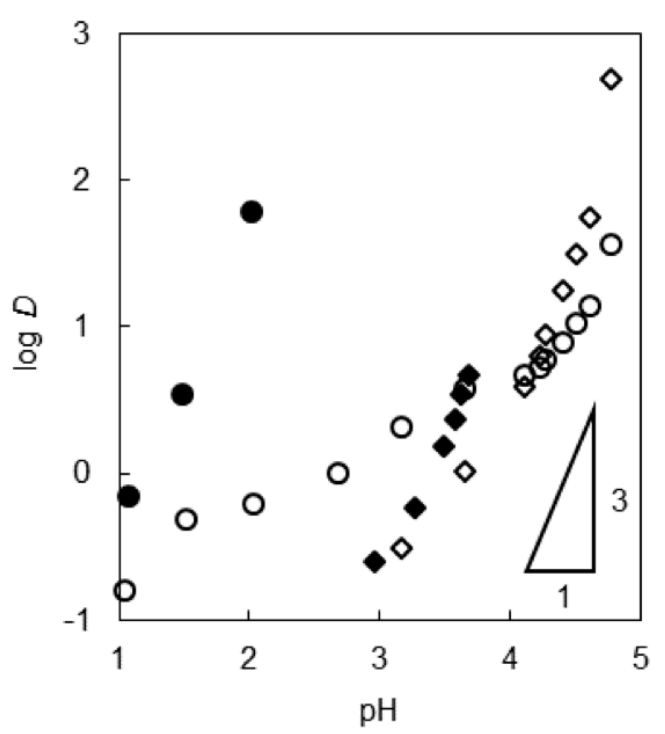

Fig. 2 Effect of shaking time on the extraction of $\mathrm{Sc}^{3+}$ and $\mathrm{La}^{3+} \cdot\left[\mathrm{Ln}^{3+}\right]=0.1 \mathrm{mmol} \mathrm{dm}^{-3},[\mathrm{HR}]=0.01 \mathrm{~mol} \mathrm{dm}^{-3}$. Sc (24h), : La (24h), O: Sc (1h), $\diamond:$ La (1h).

\subsection{Effect of $\mathbf{p H}$}

Effect of $\mathrm{pH}$ on the $\log D$ was shown in Fig. 3 and slope of the straight lines for $\log D$ vs. $\mathrm{pH}$ plots and $\mathrm{pH}_{1 / 2}$ values, which are the $\mathrm{pH}$ values at $\log D=0$ were summarized in Table 2 . Here, $D$ is distribution ratio and was calculated indirectly by using Eq.(1).

$$
D=\frac{[\mathrm{M}]_{\text {init }}-[\mathrm{M}]_{\mathrm{aq}}}{[\mathrm{M}]_{\mathrm{aq}}}
$$

$[\mathrm{M}]_{\text {init }}$ and $[\mathrm{M}]_{\mathrm{aq}}$ refer to the metal ion concentration in the original solution and in the equilibrated aqueous solution, respectively. In Table 2, the values in the parenthesis in the upper row are the slope of line and those in the lower row are $\mathrm{pH}_{1 / 2}$ value. The some values of $\mathrm{pH}_{1 / 2}$ for $\mathrm{Y}^{3+}$ and $\mathrm{Eu}^{3+}$ using typical ionic liquids were quoted from the literature ${ }^{13)}$ to evaluate the separation ability of $\mathrm{PC}$ and $\mathrm{BC}$. The extraction performance of $\mathrm{PC}$ and $\mathrm{BC}$ for $\mathrm{Y}^{3+}$ and $\mathrm{Eu}^{3+}$ were worse than that of $\left[\mathrm{C}_{4} \mathrm{~min}\right]$ and better than that of $\left[\mathrm{C}_{12} \mathrm{~min}\right]$. While, the extraction performance of $\mathrm{PC}$ for $\mathrm{Y}^{3+}, \mathrm{Eu}^{3+}$ and $\mathrm{Yb}^{3+}$ were almost similar to hexane, but that of $\mathrm{BC}$ were inferior to hexane. By using the difference of $\mathrm{pH}_{1 / 2}$ value between $\mathrm{Y}^{3+}$ and $\mathrm{Eu}^{3+}$, $\Delta \mathrm{pH}_{1 / 2(\mathrm{Y}-\mathrm{Eu})}$, separation performance of $\mathrm{PC}$ and $\mathrm{BC}$ were similar to those of ionic liquids.

In the chelate extraction system, when trivalent metal ion is extracted in the form of neutral chelate complex, overall extraction process is written as

$$
\mathrm{Ln}^{3+}+\mathrm{nHR}_{(\mathrm{o})} \leftrightarrows \mathrm{LnR}_{\mathrm{n}(\mathrm{o})}+\mathrm{nH}^{+}
$$

where $\mathrm{Ln}^{3+}$ is lanthanide ion and HR is DODGAA, and subscript (o) represents species in the organic phase, respectively. The relationship between $\log D$ vs. $\mathrm{pH}$ and 
$\log [\mathrm{HR}]_{(\mathrm{o})}$ in Eq. (2) is expressed as

$\log D=\log K_{e x}+\mathrm{n} \log [\mathrm{HR}]_{(\mathrm{o})}+\mathrm{npH}$

where $K_{\mathrm{ex}}$ is the extraction constant. Since Shimojo et al.
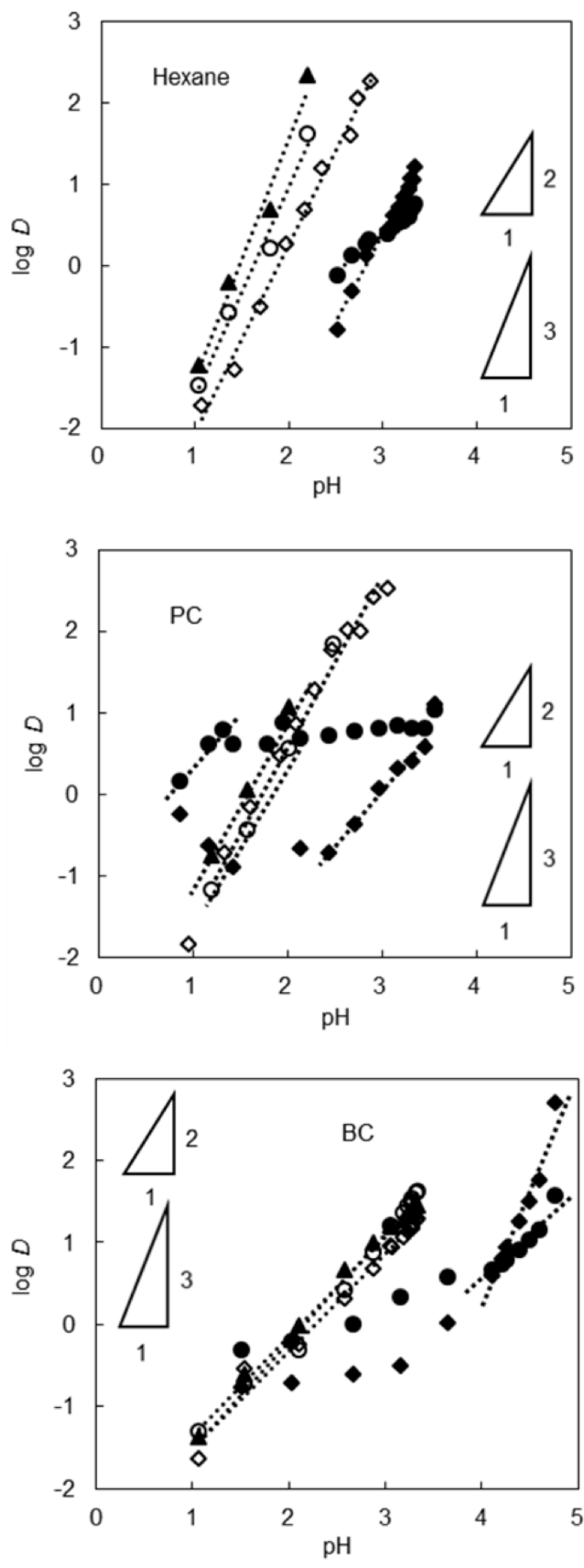

Fig. 3 Relationships between $\log D$ and $\mathrm{pH}$. $\left[\mathrm{Ln}^{3+}\right]=0.1$ $\mathrm{mmol} \mathrm{dm}{ }^{-3},[\mathrm{HR}]=0.01 \mathrm{~mol} \mathrm{dm}^{-3} . \bullet: \mathrm{Sc}, \mathrm{O}: \mathrm{Y}, \diamond: \mathrm{La}$, $\diamond:$ Eu, $\mathbf{\Delta}:$ Yb. reported that lanthanides were extracted in the form of $\mathrm{LnR}_{3}$ with DODGAA hexane solution ${ }^{12}$, the slope of straight lines for $\log D$ vs. $\mathrm{pH}$ and $\log D$ vs $\log [\mathrm{HR}]_{(\mathrm{o})}$ should be 3 theoretically. Unfortunately, most of slopes of lines for $\log D$ vs. $\mathrm{pH}$ were deviated from the theoretical value, except for those for $\mathrm{Y}^{3+}$ and $\mathrm{Yb}^{3+}$ in the DODGAA-hexane extraction system and $\mathrm{La}^{3+}$ in DODGAA-BC one. Possible causes for these deviations in the slopes of lines for $\log D$ vs. $\mathrm{pH}$ from 3 can be considered as follows: (1) PC is fairly soluble in water and then the volume change due to the mutual dissolution might affect on the metal ion concentration, and (2) different kind of complex other than $\mathrm{LnR}_{3}$ was formed and extracted into the organic phase.

\subsection{Effect of mutual dissolution}

In order to avoid the volume changes of phases by shaking, both phases were saturated with the counter phase prior to use. That is, the organic phase was shaken vigorously with same volume of $0.1 \mathrm{~mol} \mathrm{dm}{ }^{-3} \mathrm{NH}_{4} \mathrm{NO}_{3}$ aqueous solution for $2 \mathrm{~h}$ using reparatory funnel and set aside for $12 \mathrm{~h}$ to separate phases. The aqueous phase containing $0.1 \mathrm{mmol} \mathrm{dm}^{-3} \mathrm{La}^{3+}$ and $\mathrm{Eu}^{3+}$ and $0.1 \mathrm{~mol} \mathrm{dm}^{-3} \mathrm{NH}_{4} \mathrm{NO}_{3}$ was also treated with $\mathrm{PC}$ in a similar manner to the organic phase. After that, both phases were subjected to extraction.

The slope of the straight line in $\log D$ vs. $\mathrm{pH}$ for $\mathrm{La}^{3+}$ and $\mathrm{Eu}^{3+}$ were 1.6 and 2.0, and $\mathrm{pH}_{1 / 2}$ value for $\mathrm{La}^{3+}$ and $\mathrm{Eu}^{3+}$ were 2.77 and 1.75 , respectively. The slopes of lines obtained by using pretreatment of phases could not be improved satisfactorily from those obtained by using the untreated phases (Table 2), although the $\mathrm{pH}_{1 / 2}$ value of $\mathrm{La}^{3+}$ was slightly changed. It can be elucidated as follows. In this study, $[\mathrm{M}]_{\text {init }}$ in Eq.(1) was determined by using the pretreated aqueous phase containing $0.1 \mathrm{mmol} \mathrm{dm}^{-3} \mathrm{Ln}^{3+}$ and $0.1 \mathrm{~mol} \mathrm{dm}^{-3} \mathrm{NH}_{4} \mathrm{NO}_{3}$ by equilibrating with pure $\mathrm{PC}$ in accordance with usual extraction procedure. Therefore, the impact of the volume change on $\mathrm{Ln}^{3+}$ concentration due to mutual dissolution has already been discounted.

Table 2 Value of $\mathrm{pH}_{1 / 2}$ and slope of $\log D$ vs. $\mathrm{pH}$ curve.

\begin{tabular}{|c|c|c|c|c|c|}
\hline Solvent & $\mathrm{Sc}$ & $\mathrm{La}$ & $\mathrm{Y}$ & $\mathrm{Eu}$ & $\mathrm{Yb}$ \\
\hline \multirow{2}{*}{ Hexane } & $(0.9)$ & $(2.2)$ & $(2.6)$ & $(2.3)$ & $(3.0)$ \\
& 3.14 & 2.82 & 1.63 & 1.89 & 1.47 \\
\hline \multirow{2}{*}{$\mathrm{PC}$} & $(1.4)$ & $(1.5)$ & $(2.3)$ & $(2.1)$ & $(2.2)$ \\
& 0.74 & 2.95 & 1.73 & 1.71 & 1.54 \\
\hline \multirow{2}{*}{$\mathrm{BC}$} & $(1.4)$ & $(3.0)$ & $(1.3)$ & $(1.2)$ & $(1.2)$ \\
& & 3.95 & 2.16 & 2.28 & 2.12 \\
\hline$\left[\mathrm{C}_{4} \mathrm{~min}\right]^{\text {a) } 13)}$ & & & 1.05 & 1.17 & \\
\hline$\left[\mathrm{C}_{12} \mathrm{~min}\right]^{\mathrm{b}) 13)}$ & & & 2.23 & 2.26 & \\
\hline
\end{tabular}

a) 1-Butyl-3-methylimidazolium bis(trifluoromethanesulfonyl)imide. b) 1-Dodecyl-3-methylimidazolium bis(trifluoromethanesulfonyl)imide. 

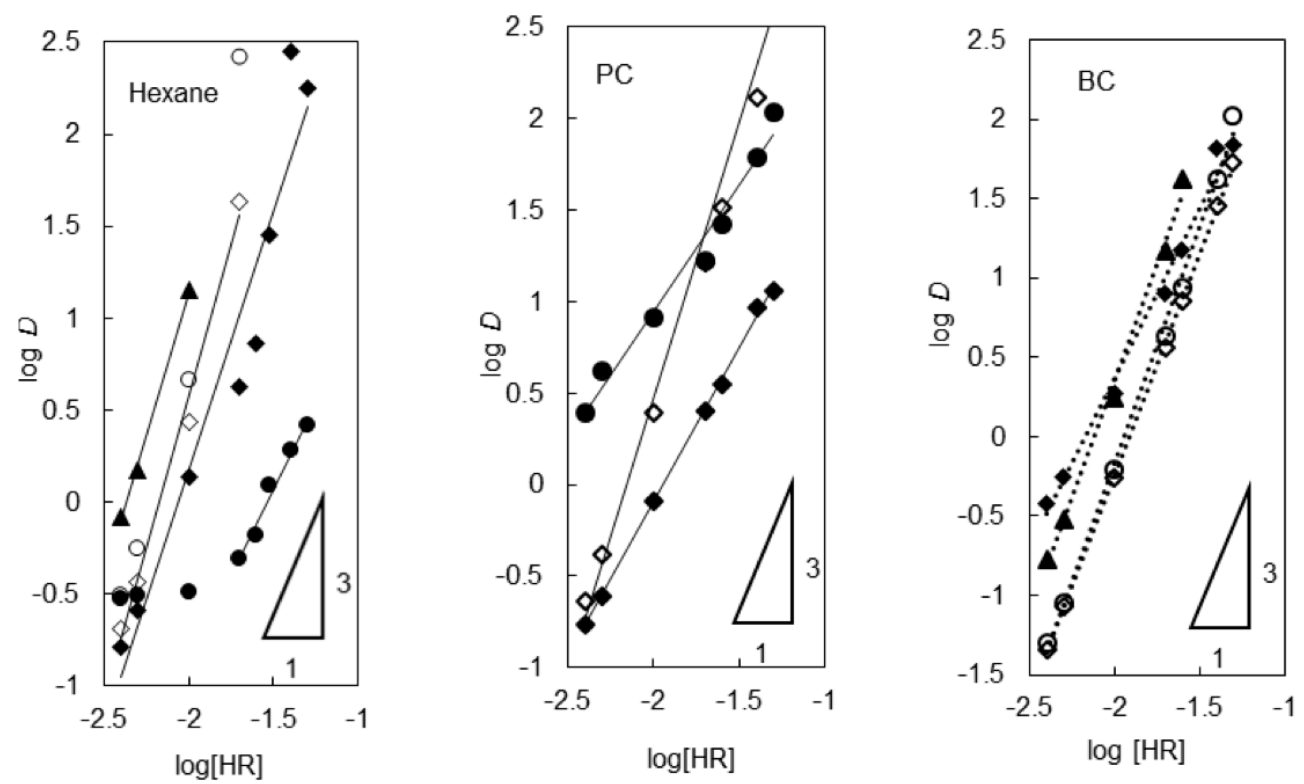

Fig. 4 Effect of concentration of DODGAA on the distribution ratio of metal ion. $\left[\mathrm{M}^{3+}\right]=0.1 \mathrm{mmol}$ $\mathrm{dm}^{-3},[\mathrm{HR}]=0.004-0.05 \mathrm{~mol} \mathrm{dm}^{-3} . \bullet: \mathrm{Sc}, \mathrm{O}: \mathrm{Y}, \diamond: \mathrm{La}, \diamond: \mathrm{Eu}, \Delta: \mathrm{Yb}$.

\subsection{Effect of DODGAA concentration}

Next, in order to certify the possibility of the formation of complex with the composition except $\mathrm{LnR}_{3}, 3$ kinds of experiments were undertaken. First, in order to determine the constitution of extracted complex, the relationship between DODGAA concentration and distribution ratio was determined. As can be seen in Fig. 4, most of the slope for the straight line for $\log D$ vs. $\log [\mathrm{HR}]_{(\mathrm{o})}$ are closed to 3. The slope of the line in $\log D$ vs. $\mathrm{pH}$ plots was close to 2 for $\mathrm{Eu}^{3+}$ in hexane system and $\mathrm{Y}^{3+}, \mathrm{Eu}^{3+}$ and $\mathrm{Yb}^{3+}$ in $\mathrm{PC}$ system, and that was closed to 1 for $\mathrm{Y}^{3+}, \mathrm{Eu}^{3+}$ and $\mathrm{Yb}^{3+}$ in $\mathrm{BC}$ system (Table 2).

In order to logically explain the discrepancy between in slopes with $\log D$ vs. $\mathrm{pH}$ and $\log D$ vs. $\log [\mathrm{HR}]_{(\mathrm{o})}$, the possibility of complexes having different composition from $\mathrm{LnR}_{3}$ must be considered. In the former case, the extracted complex is thought to be contained 2 dissociated DODGAA molecules, 1 unknown anion, $\mathrm{X}^{-}$, and 1 neutral DODGAA molecule.

$\mathrm{Ln}^{3+}+\mathrm{nHR}_{(\mathrm{o})}+\mathrm{X}^{-} \leftrightarrows \operatorname{LnXR}_{(\mathrm{n}-1)} \mathrm{HR}_{(\mathrm{o})}+(\mathrm{n}-1) \mathrm{H}^{+}$

In the latter case, the extracted complex possibly contained 1 dissociated DODGAA molecules, $2 \mathrm{X}^{-}$, and 2 neutral DODGAA molecule.

$$
\mathrm{Ln}^{3+}+\mathrm{nHR}_{(\mathrm{o})}+2 \mathrm{X}^{-} \leftrightarrows \mathrm{LnX}_{2} \mathrm{R}_{(\mathrm{n}-2)} 2 \mathrm{HR}_{(\mathrm{o})}+(\mathrm{n}-2) \mathrm{H}^{+}
$$

It is well known that polar solvent such as nitrobenzene extracts ion association complex consisting of complex ion and counter ion ${ }^{18)}$. PC and $\mathrm{BC}$ are highly polar, so that $\mathrm{Ln}^{3+}$ could be extracted in the form of species written in Eqs. (4) and (5).

\subsection{Effect of nitrate concentration}

Second, in order to clarify the presence of the complexes containing anion other than dissociated DODGAA, effect of
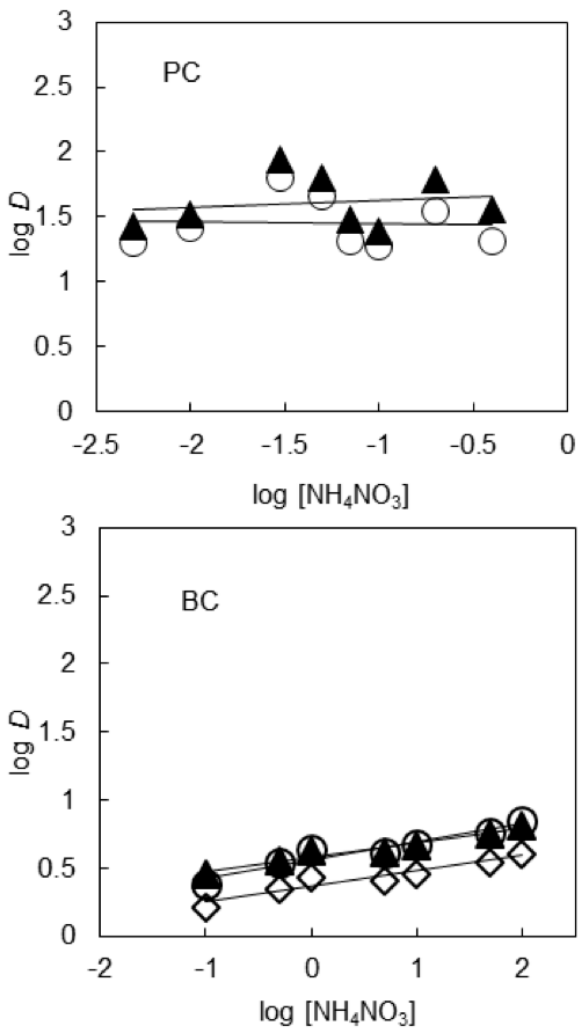

Fig. 5 Effect of concentration of $\mathrm{NH}_{4} \mathrm{NO}_{3}$ in aqueous phase on the distribution ratio. $\left[\mathrm{Ln}^{3+}\right]=0.1 \mathrm{mmol} \mathrm{dm}^{-3},[\mathrm{HR}]=$ $0.1 \mathrm{~mol} \mathrm{dm}^{-3}, \mathrm{pH} 2.77 \pm 0.01$ in PC system. $\left[\mathrm{Ln}^{3+}\right]=0.1$ $\mathrm{mmol} \mathrm{dm}{ }^{-3},[\mathrm{HR}]=0.01 \mathrm{~mol} \mathrm{dm}^{-3}, \mathrm{pH} 2.91 \pm 0.03$ in BC system. O: Y, $\diamond:$ Eu, $\Delta$ : Yb. 
nitrate concentration on the extractions of $\mathrm{Y}^{3+}, \mathrm{Eu}^{3+}$ and $\mathrm{Yb}^{3+}$ in the $\mathrm{PC}$ and $\mathrm{BC}$ extraction systems were examined, since $\mathrm{NH}_{4} \mathrm{NO}_{3}$ was added into the aqueous phase in order to maintain ionic strength. Fig. 5 shows the relationship between $\log D$ and the logarithm of nitrate concentration and demonstrates that the slopes of all line are close to 0 . This means that nitrate ion was not involved in this extraction process.

\subsection{HPLC-MS}

Thirdly, the attempt to determine the composition of extracted complex by the slope analysis was unsuccessful, then the structural analysis of the extracted complex into hexane and $\mathrm{BC}$ was carried out by using HPLC-MS. The analytical conditions of HPLC-MS were listed in Table 3. Four samples

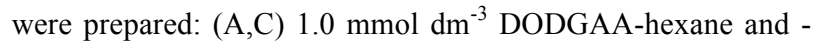
$\mathrm{BC}$ solution equilibrated with $0.1 \mathrm{~mol} \mathrm{dm} \mathrm{NH}_{4} \mathrm{NO}_{3}$ aqueous solution and (B,D) $1.0 \mathrm{mmol} \mathrm{dm}^{-3}$ DODGAA-hexane and -BC solution equilibrated with aqueous solution containing $0.1 \mathrm{~mol}$ $\mathrm{dm}^{-3} \mathrm{NH}_{4} \mathrm{NO}_{3}$ and $0.1 \mathrm{~mol} \mathrm{dm}^{-3} \mathrm{Yb}^{3+}$, respectively. Figure 6 shows the chromatogram of organic phases detected by the total ion current. The peak at around 0.9 min was observed in all organic phases and was identified to be DODGAA based on $\mathrm{MH}^{+}$of 358.2961. The peak of $\mathrm{Yb}^{3+}$-DODGAA complex could not be detected with either of hexane and PC solution. Although the broad peak was observed in the DODGAAhexane solution (Fig.6-B), but the fragmentation due to the isotope abundance ratio of $\mathrm{Yb}$ was not appeared. The nondetection of extracted $\mathrm{Yb}^{3+}$-complex may be ascribed to the failure in ionization of complex under the operating condition.
Table 3 HPLC and MS analytical conditions.

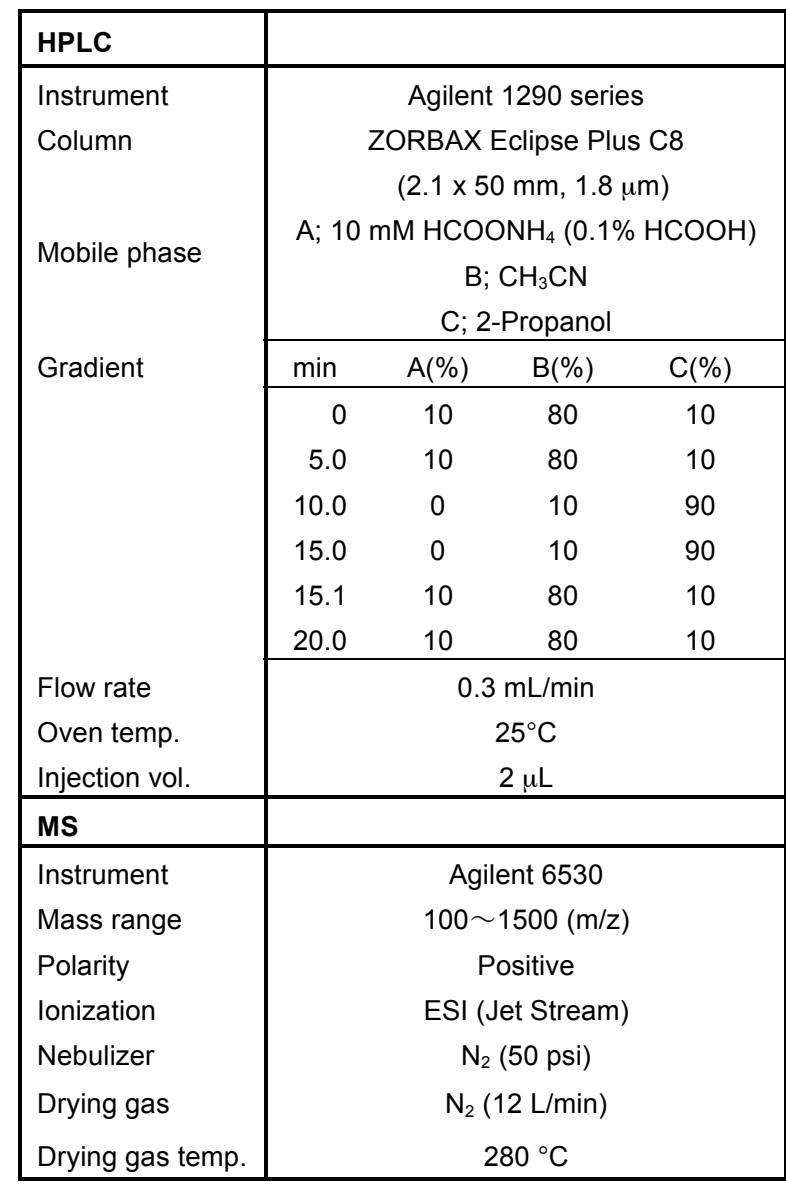

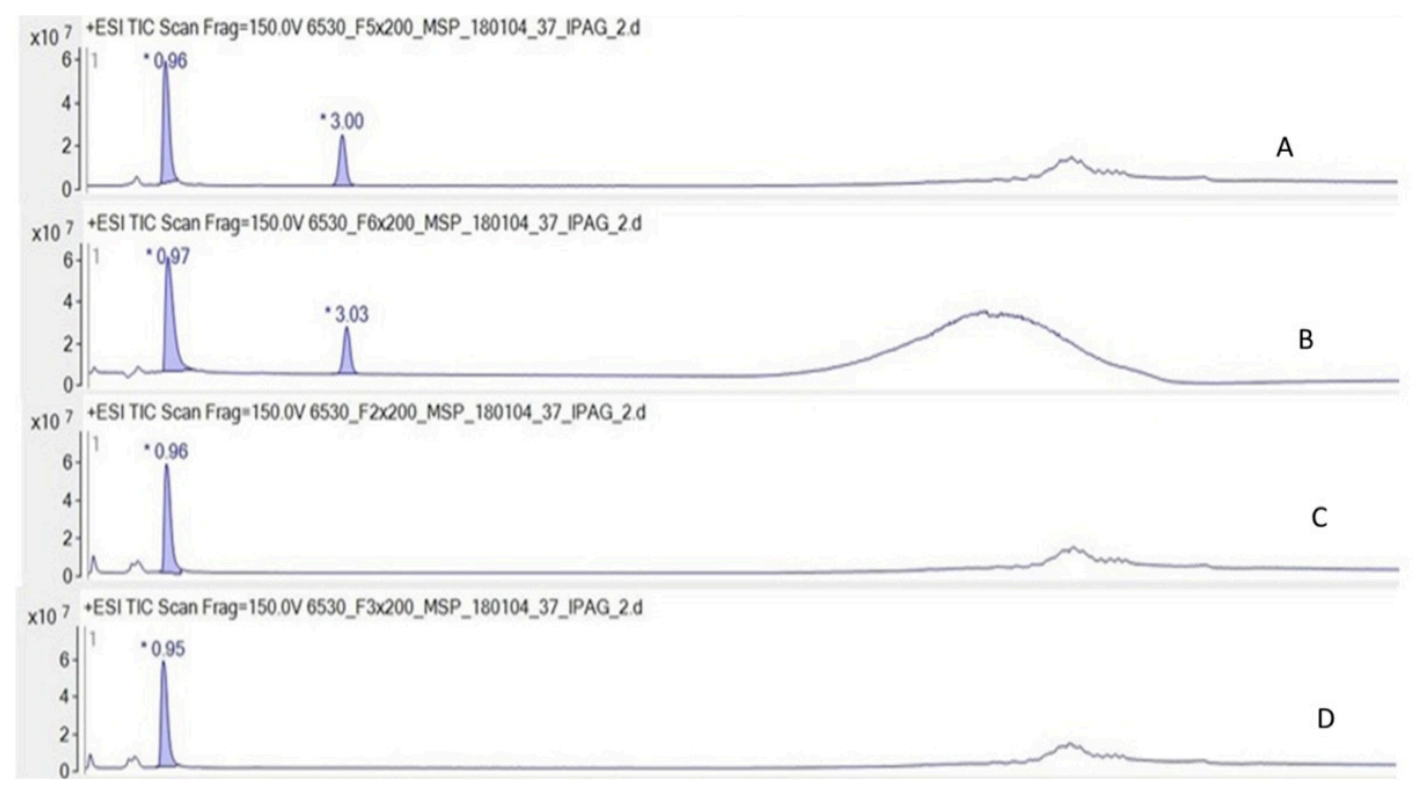

Fig. 6 Total ion chromatogram obtained with gradient mode for the equilibrated organic phase.
A: DODGAA-hexane solution equilibrated with $\mathrm{NH}_{4} \mathrm{NO}_{3}$ aqueous solution.
B: DODGAA-hexane solution equilibrated with aqueous solution containing $\mathrm{NH}_{4} \mathrm{NO}_{3}$ and $\mathrm{Yb}^{3+}$.
C: DODGAA-BC solution equilibrated with $\mathrm{NH}_{4} \mathrm{NO}_{3}$ aqueous solution.
D: DODGAA-BC solution equilibrated with aqueous solution containing $\mathrm{NH}_{4} \mathrm{NO}_{3}$ and $\mathrm{Yb}^{3+}$. 


\section{Conclusion}

The extraction performance of $\mathrm{PC}$ and $\mathrm{BC}$ was examined with DODGAA extraction of $\mathrm{Ln}^{3+}$. Since $\mathrm{PC}$ and BC are heavy solvent, the handling of aqueous phase, e.g., the measurement of $\mathrm{pH}$ and sampling of aqueous phase for the back extraction and for determination of $\mathrm{Ln}^{3+}$ concentration after equilibration, was much convenient compared to the usual light solvents such as hexane, toluene and so on. The extractability of PC and BC on the extraction most strongly appeared for $\mathrm{Sc}^{3+}$ and therefore, the separation of $\mathrm{Sc}^{3+}$ from other lanthanides also fairly varied from that in hexane extraction system. However, the quantitative results could not be obtained in the slope analysis, and several examinations including HPLC-MS analysis could not explain the reason why the slope of the straight line in the slope analysis differed from theoretical value of 3. Although some problems still remains unsolved in the slope analysis, this study explicitly shows that PC and BC are capable solvent of providing a different extraction mode from the usual solvents.

\section{References}

1) Sciencelab.com, Inc., Material Safety Data Sheet Propylene carbonate MSDS,

http://www.sciencelab.com/msds.php?msdsId=9927238.

2) For example, S. H. Ali, H. M.S. Lababidi, S. Q. Merchant and M. A. Fahim, Fluid Phase Equilib., 214, 25-38 (2003).

3) B. G. Stephens and H. A. Suddeth, Anal. Chem., 39, 14781480 (1967).

4) B. G. Stephens, J. C. Loftin, W. C. Looney and K. A. Williams, Analyst, 96, 230-234 (1971).

5) B. G. Stephens, H. L. Felkel and Jr., W. M. Spinelli, Anal. Chem., 46, 692-696 (1974).

6) Y. Nagaosa, N. Yoshida, Y. Maegawa and T. Fuwa, Mikrochim. Acta, 83, 39-46 (1984).

7) Y. Nagaosa and K. Horita, Mikrochim. Acta, 108, 151-156 (1992).

8) K. Murata, Y. Yokoyama and S. Ikeda, Anal. Chem., 44, 805-810 (1972).

9) Y. Nagaosa and N. Sato, Bunseki Kagaku, 36, 877-879, (1987) (in Japanese).

10) K. Shimojo, A. Nakai, H. Okamura, T.Saito, A. Ohashi and H. Naganawa, Anal. Sci., 30, 513-517 (2014).

11) K. Shimojo, N. Aoyagi, T. Saito, H. Okamura, F. Kubota, M. Goto and H. Naganawa, Anal. Sci., 30, 1-4 (2014).

12) K. Shimojo, N. Aoyagi, T. Saito, H. Okamura, F. Kubota, M. Goto and H. Naganawa, Anal. Sci., 30, 263-268 (2014).

13) F. Kubota, Y. Shimobori, Y. Baba, Y. Koyanagi, K. Shimojo and N. Kamiya, M. Goto, J. Chem. Eng. Jpn, 44, 307-312 (2011).

14) T. Asahara, N. Tokura, M. Okawara, J. Kumanotani and M. Senoo, "Yozai Handbook", Kodansha, Tokyo (1998), pp. 149, 182, 374, 627, 640, 855 (in Japanese).
15) http://www.tcichemicals.com/eshop/en/in/commodity/ B3321/

16) I. M. Smallwood, "Handbook of organic solvent properties”, Arnold, London (1996), pp. 7, 39, 101.

17) I. Matsuoka, T. Naito and H. Yamada, Bunseki Kagaku, 51, 759-765 (2002) (in Japanese).

18) T. Sekine and Y. Hasegawa, Yukagaku, 39, 729-735 (1990) (in Japanese). 